effect of reducing rates, and will do so still more, for the charges have not yet reached bed-rock. When this desirable result has been achieved, the Yellowstone National Park will become one of the most popular resorts for tourists of all nations, who will be amply repaid by an inspection of one of the few remaining regions of the earth where thermal activity still reaches its surface, and of the grand and impressive scenery which surrounds it.

\title{
AN OBSERVATION ON THE HYBRIDIZATION AND CROSS-BREEDING OF PLANTS. ${ }^{+}$
}

BY E. LEWIS STURTEVANT, M.D.

GEORG von Martens, in his Gartenbohnen, Ravensburg, I 869,

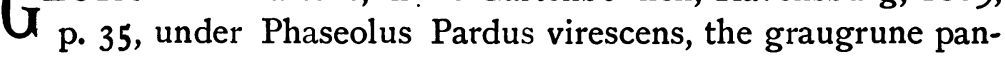
therbohne, says: "I was very much surprised to obtain not less than eight varieties of beans, die incarnatbohne, die dottergelbebohne, die weissebohne, die amethystfarbige zebrabohne, die graugrune pantherbohne, die helle pantherbohne, die gelbgefleckte pantherbohne, and the princessinbohne. With more thorough investigation $I$ decided that the zebrabohne was most likely a neighbor which had overrun the bed, but all the others came from the bed, and some, the incarnatbohne and the weissebohne had not been planted in the whole garden." Martens might have expressed surprise that these varieties from the seed of the graugrune pantherbohne were all towards named varieties rather than sports or intermediates, but this fact, which frequently appears noted in his book, does not receive attention as being of any importance.

At the New York Agricultural Experiment Station, in 1882, a few oblong beans, slightly flattened sidewise and mottled in two shades of brown, were selected from the yield of the golden cranberry. This selection, planted by itself in 1883 , gave eleven distinct forms, many of which can be referred to named varieties, and possibly with a greater acquaintance with varieties all might be so referred; an illustration confirmatory of the results above noted by Martens, and is strengthened by a list of similar occurrences with other varieties in 1883 numbering a score.

This fact of named varieties being produced from seed of other varieties is not confined to the bean family alone. The following

1 Read before section F, A. A. A. S. at the Ann Arbor meeting. 
list includes similar occurrences noted at the New York Agricultural Experiment Station during the last three years :

Maize.-Seed of one kind sown often produces samples of other kinds of corn in the crop, and these varieties can usually be distinctly referred by name to varieties with which the original seed might have been crossed. Purposely hybridized seed has produced the original parentage without intermediate types, and seed exposed to hybridization during two years with many sorts of corn, has yielded ears of the types of corn with which crossbreeding or hybridization has been effected, without appearance of intermediate forms.

Barley.-April, I884, one head of cross-bred awnless barley was received from Mr. Horsford, a seed-grower in Vermont. The yield of the twenty-six seed was four distinct sorts of barley; one beardless black, one beardless white, one bearded black and one bearded white. One peculiarity was, that the beardless forms could be referred to Hordeum trifurcatum. There were no intermediates in this crop.

Peppers.-In I 882 eleven varieties of peppers were grown; in I 883, nineteen varieties. The pepper plant is extremely variable. The fruit on different plants of the same variety often varies much in shape; on some the fruit is borne erect, on others pendant; certain plants of a variety often mature their fruit much earlier than do others. These facts, as well as direct observation, certify to the ready cross-fertilization between varieties. Yet despite this apparent cross-fertilization, varieties by selection are kept true to name, and almost all or perhaps all of the various "sporting" forms noted by us are found illustrated in Hortus Eystettensis, I6I3, a fact which brings the pepper in line with our other illustrations.

\section{Tomato. ${ }^{1}$ - In 1882 the French upright tomato was crossed with}

${ }^{1}$ Some additional observations of a later date than those given in this paper are as follows :

Melon.-The Christiana melon seed used in 1885 was from two sources. The one seed pure and the crop all on type; the other seed station-grown in 1883 and subjected to a possible cross-fertilization with other varieties; the produce from this seed gave this year fruit mostly of pure Christiana type, but some plants yielded fruit of the early white Japan, long Persian and Hackensack types, and no intermediates. These oft-varieties were among the melon varieties of 1883 , and by which there was a possibility of the Christiana being crossed through insect agency.

Tomato.-In 1883 the French upright tomato was crossed by the Livingston's favorite, and the crossed seed has been attempted to be grown in purity up to date. 
pollen from the alpha and Livingston's favorite. The produce from the cross-breds was one plant of the French upright, a hundred or more of the common form, and no intermediates. The fruit was all clustered, however, and of one type of bearing. The types of the tomato fruit have not as yet been sufficiently studied by us to allow of a judgment upon variability in this respect.

Squash. - In 1883 the perfect gem and vegetable marrow squashes were crossed in both directions. The seed planted in I 884 gave good types of the cocoanut, green-striped bergen and the courge d'Italie varieties. In 1883 , the year the seed was saved, we had no plants of these varieties upon the station grounds. There were also some unknown forms, but none that could be called strictly intermediate between the varieties, and some which represented each parentage.

Lettuce.-In 1883 the green fringed and the deer tongue lettuce was crossed. In 1884 the crop yielded forms which could be referred to the Batavian, Silesian and Malta drumhead varieties,

This year is hence the second generation from the cross. The number of plants under observation have been numerous, occupying three-twentieths of an acre. The types of the plants are French upright and the common, without intermediate forms. The types of the fruit are French upright, Livingston's favorite, common red and great Chihuahua, and no intermediates that can be recognized. The last-named is precisely on type both in plant and fruit, but few plants as compared with the others.

French upright crossed by acme. First generation. The types of plant either French upright or acme. The fruit acme, French upright and common red, and no intermediates.

French upright crossed by alpha. Second generation. The type of plant both kinds. The French upright type of plants have all French upright type of fruit. The common type of plants bear fruit of the fig, pear, plum, alpha, common red, French upright and great Chihuahua type, and no intermediates that can be recog. nized.

Currant crossed by Livingston's favorite. First generation. The types of plant mostly the currant, but some few plants of the common form, but slightly more upright. The fruit is racemed like the currant, but of far larger size, about $11 / 8$ inch in diameter. Although I have never seen fruit of this character before, yet the plant and the fruit correspond very closely with the description of the Solanum racemosum cerasorum forma of Bauhin's Prodromus, ed. of 1671, p. 90; and we may legitimately suspect atavism has reproduced this apparently lost variety.

Turks cap crossed by several large varieties in 1882 , such as acme, trophy, mayflower and paragon. The first generation was grown in the greenhouse, and hence the crop of 1885 is the fourth generation, the selections having been made each year for soundness and smoothness of fruit. The foliage of the 1885 plants somewhat variable but of the common type. The fruit can be referred to the apple, acme and common red. One plat from the earliest seed of this class has given constant foliage, and the fruit small, of the plum variety type, and of constant form. 
and there were no intermediates between the parents. In this case we had the parents of two very distinct types, there being scarcely a point of resemblance in general appearance.

Pea.-In I 883 we had crosses between the sugar pea and the common pea. The I 884 crop from the crossed seed had the seed all of the sugar pea type, the pods all of the common type. The wrinkled pea crossed with the smooth pea gave wrinkled and smooth peas in the same pod, but no merging of the two forms.

These facts of careful observation and record are only explainable by the hypothesis that in certain kinds of cross-fertilizations and hybridizations the tendency of the crossed seed is to reproduce ancestral forms rather than intermediate forms. That there can be a blending of characters in certain cases is well known or certainly well asserted; but in the experience gained at the New York Agricultural Experiment Station, "sports" or blendings are rare in exact accordance with our familiarity with varieties. Thus in the case of the maize, at first we had many cases noted in our collection as variables; with the increase of varieties grown, and with increased specimens in our museum collection, these variables, almost without exception, could be referred to types or varieties, and the few exceptions to this statement occur in the little-studied class of pod or husk corns. Two illustrations will suffice: in New Jersey an excellent farmer there noticed a few pod ears in his crop of Blount's prolific dent and forwarded samples to the station as novelties. The seed from these pod ears reproduced with us Blount's prolific of perfect type and pod corn of the same type of ear which furnished the seed, and no variables from the two types noted. From the crossing of pod corn with sweet corn a new variety of sweet corn was produced, of a distinct type and esteemed by us a novelty in every respect, the cob being fusiform, the kernels horse tooth and much wrinkled, the stalk very small. At a later date this type appeared in our collections as the banana sugar, and was proven not to be original with us.

Darwin, in his Animals and Plants under Domestication, the New York edition of i 868, Vol. II, p. 54, has a section entitled, "Crossing as a direct cause of Reversion," and says: "But that the act of crossing in itself gives an impulse toward reversion, as shown by the reappearance of long-lost characters, has never, I believe, been hitherto proved." His line of evidence, however, 
is different from that here presented, and embraces a different series of observations.

The lack of agricultural museums in which domesticated varieties of plants find representation, the general ignorance of the varieties which were grown by our predecessors, and the in general careless descriptions which occur in the writings on agriculture, render a study of this sort embarrassing and difficult. A careful study, however, of the figures given by the botanists of the sixteenth century and thereafter, and a careful collation of evidence gleaned from more recent authors on gardening, together with the fact that the appearance of new form-species of cultivated vegetables seems to date from the introduction of forms of the same species from distant regions, and the rarity of appearance of novelties which cannot be identified with some previously described type, ${ }^{1}$ all encourage to the belief in the correctness of the generalization that in our domesticated vegetable plants crossfertilization shows its effect at once in the reproduction of the form-species and varieties which are involved in the parentage of the crossed seed, and that when "pure seed" is crossed intermediate forms rarely occur, but the original parents in variable proportions.

\section{- \\ OBSERVATIONS ON THE MUSKRAT. ${ }^{2}$}

BY AMOS W. BUTLER.

THE muskrat (Fiber zibethicus Cuv.) is very abundant in most 1 localities in Southeastern Indiana. In local distribution it varies in numbers according to the abundance of water and favorable localities for its increase. From all that I can learn, I do not think it is less common than at the time of the early settlement of this region.

These animals soon became acquainted with man and, from experience, learned that his presence assured them a great abundance of food at much less labor than formerly, while, at the same time, their natural enemies decreased in numbers on account of his necessity and pleasure. In some localities, owing to the perse-

${ }^{1}$ For instance, the deer tongue lettuce, with lanceolate leaves, which appeared about $\mathrm{I} 883$, is almost identical with the Lactuca folio oblongo acuto figured in Bauhin's Prodromas, edition of 1671, p. 60.

${ }^{2}$ Read before the section of Biology of the American Association for the Advancement of Science at Ann Arbor, Mich., Aug. 27, 1885. 